Check for updates

Cite this: RSC Adv., 2018, 8, 39140

Received 31st August 2018

Accepted 7th November 2018

DOI: $10.1039 / c 8 r a 07263 a$

rsc.li/rsc-advances

\section{Aggregation prevention: reduction of graphene oxide in mixed medium of alkylphenol polyoxyethylene (7) ether and 2-methoxyethanol $\uparrow$}

\author{
Heng Su, ${ }^{a}$ Chaocan Zhang, (D) *a Xi Li, (D) ${ }^{b}$ Lili Wu and Yanjun Chen ${ }^{a}$
}

Graphene has attracted great interest due to its extensive applications in optoelectronic and electronic circuits and devices. However, reduction of graphene oxide (GO) to graphene is a process in which hydrophilic GO converts to hydrophobic graphene. Very little is known about the aggregation of graphene and the cause of performance degradation by general chemical reduction methods as the single reaction medium presents difficulty in satisfying the good dispersion of hydrophilic GO and hydrophobic graphene simultaneously. In this paper, we report a mixed medium of alkylphenol polyoxyethylene (7) ether (OP-7) and 2-methoxyethanol (EGM) for the preparation of graphene. The strong polar nature of EGM provides a good dispersion environment for GO, while the $\pi-\pi$ interaction between the $\pi$-electrons in nonionic surfactant OP-7 aromatic ring structure and the $\pi$-electrons in graphene make the hydrophobic graphene well dispersed and prevent aggregation. Moreover, the reduction temperature is not high and the reduction time is short. The electrical conductivity of graphene without high-temperature treatment reached $14000 \mathrm{~S} \mathrm{~m}^{-1}$. We have found the potential reduction mechanism of graphene and fundamentally solved the problem of aggregation. Our findings make it possible to process graphene materials using low-cost mixed medium processing techniques, providing a valuable reference for the large-scale preparation of graphene.

\section{Introduction}

Graphene is a one-atom-thick planar sheet of $\mathrm{sp}^{2}$-hybridized carbon atoms arranged hexagonally. Graphene has extraordinary electrical, thermal, mechanical and other properties due to its unique two-dimensional crystal structure, ${ }^{1,2}$ and it has emerged as an attractive material in electronics, optoelectronics and capacitors. ${ }^{3,4}$ Among its various properties, the distinctive electronic properties of graphene has great potential applications in high-electron-mobility transistors, ${ }^{5}$ supercapacitors $^{6-8}$ and solar cells. ${ }^{9,10}$ Up to now, several fabrication routes for the production of graphene have been established, such as mechanical exfoliation, ${ }^{11-13}$ chemical reduction of graphene oxide solution, ${ }^{14-17}$ epitaxial growth $^{18,19}$ and chemical vapor deposition. ${ }^{20,21}$ The chemical reduction method plays an important role in the prospect of potential industrialization.

${ }^{a}$ Department of Materials Science and Engineering, Wuhan University of Technology, Wuhan 430070, China. E-mail: polymers@whut.edu.cn; suhengwhut@163.com; poly_wl@whut.edu.cn; yanjunchen@whut.edu.cn; Fax: +86878 63157; Tel: +86878 63157

${ }^{b}$ Department of Chemical Engineering and Life Sciences, Wuhan University of Technology,Wuhan 430070, China.E-mail: chemlixi@whut.edu.cn

$\dagger$ Electronic supplementary information (ESI) available. See DOI: $10.1039 / \mathrm{c} 8 \mathrm{ra} 07263 \mathrm{a}$
The chemical reduction method involves oxidizing graphite to form GO, and then reducing GO. Preparation of GO is conducted by methods such as Hummers method, ${ }^{22}$ Brodie method $^{23}$ and Staudenmaier method ${ }^{24}$ and then, the reduction of GO (RGO) is realized by using hydrazine, ${ }^{25}$ hydrohalic acid ${ }^{26}$ and sodium borohydride ${ }^{27}$ as reducing agents. Until now, hydrazine hydrate, the most widely used reducing agent, was used in aqueous medium as a reductant to reduce GO $\left(\mathrm{RGO}_{\mathrm{H} 2 \mathrm{O}}\right)$. Previous studies have reported that RGO shows a distinct sharp peak between the $23.0^{\circ}$ and $24.9^{\circ}$ region of the XRD spectrum, ${ }^{27-32}$ indicating that they have an ordered layer structure, and the electrical conductivity at room temperature is generally between 200 and $7200 \mathrm{~S} \mathrm{~m}^{-1} .{ }^{25,29,33-36}$ The value of conductivity fluctuates greatly, but the reason for this has not been studied in literature. In our opinion, ideal single-layer graphene should not have a typical layered structure, so there should be no sharp peak in the XRD spectrum. The edge of the graphite sheet is preferentially oxidized during the graphite oxidation stage, resulting in the oxidation degree of GO being higher than that in the middle region. ${ }^{37,38}$ Therefore, the edge portion of GO will be preferentially reduced to hydrophobic graphene structure, while the middle region will be reduced slowly. Finally, the structure of RGO is hydrophobic in the marginal area, while the intermediate area is hydrophilic and due to the interaction forces between hydrophobic regions, RGO tends to overlap and aggregate into a layered structure. 
This shows that the reduction of GO to RGO is a process where hydrophilic GO gets converted to hydrophobic RGO. Not only polar but also non-polar single reaction medium presents difficulties in satisfying the requirements of good dispersion for RGO. Furthermore, preventing aggregation during the reduction phase is the key to preparing RGO with excellent performance.

In this study, we designed a mixed medium that can simultaneously satisfy the well-dispersed hydrophilic GO and also prevent superimposed aggregation during the reduction process: OP-7 and EGM were mixed and used as the reaction medium and hydrazine hydrate was used as the reducing agent to reduce GO ( $\left.\mathrm{RGO}_{\mathrm{OP}-7 / \mathrm{EGM}}\right)$. The strong polar nature of EGM provided a good dispersion environment for GO, while the $\pi-\pi$ interaction between the $\pi$-electrons in the OP-7 aromatic ring structure and the $\pi$-electrons in the RGO enabled the effective dispersion of hydrophobic graphene in the reaction medium and prevented superimposed aggregation. The reduction routes and aggregation prevention mechanism are shown in Fig. 1. As a result, the XRD spectrum of the as-prepared $\mathrm{RGO}_{\mathrm{OP}-7 / \mathrm{EGM}}$ shows a broad diffraction peak between the $22.0^{\circ}$ and $26.9^{\circ}$, indicating that there is no typical layered structure. Furthermore, the reduction temperature is not high and the reduction time is short. The electrical conductivity of graphene prepared without high-temperature treatment was $14000 \mathrm{~S} \mathrm{~m}^{-1}$.

\section{Experimental section}

\section{Chemicals and materials}

Natural crystalline flake graphite (NG) (99.85\% purity, 325 mesh), sulfuric acid $\left(\mathrm{H}_{2} \mathrm{SO}_{4}, 98 \%\right)$, phosphoric acid $\left(\mathrm{H}_{3} \mathrm{PO}_{4}, \geq\right.$ $85 \%)$, hydrochloric acid ( $\mathrm{HCl}, 36 \%)$, anhydrous ethanol ( $\geq 99.7 \%$ ), 2-methoxyethanol (EGM $\geq 99 \%$ ), hydrazine hydrate $\left(\mathrm{N}_{2} \mathrm{H}_{4} \cdot \mathrm{H}_{2} \mathrm{O}, 85 \%\right)$, hydrogen peroxide $\left(\mathrm{H}_{2} \mathrm{O}_{2}, 30 \%\right)$, potassium permanganate $\left(\mathrm{KMnO}_{4}\right)$ and barium chloride $\left(\mathrm{BaCl}_{2}\right)$ were purchased from Sinopharm Chemical Reagent Co., Ltd. Alkylphenol polyoxyethylene (7) ether (OP-7) was purchased from Wen Hua Chemical Reagent Factory. Pure water with a frequency of $50 \mathrm{~Hz}$ (KQ-50, Kunshan Ultrasonic Instruments Co.) was used in all experiments.

\section{Synthesis and dispersion of GO}

GO was synthesized from natural crystalline flake graphite (NG) by a modified Hummers method. ${ }^{22}$ NG $(1 \mathrm{~g})$ and potassium permanganate $(5 \mathrm{~g})$ were added in a mixture of sulfuric acid (98\%, $81 \mathrm{~mL}$ ) and phosphoric acid ( $\geq 85 \mathrm{wt} \%, 9 \mathrm{~mL}$ ), producing a slight exothermic reaction, which increased the temperature to $30-40{ }^{\circ} \mathrm{C}$. The reaction was then heated to $50{ }^{\circ} \mathrm{C}$ without subsequent aging and stirred for $12 \mathrm{~h}$. The reaction was then cooled to room temperature and hydrogen peroxide $(30 \%, 2 \mathrm{~mL})$ was added. The next processes, namely, filtration through qualitative filter paper (GEB Co.), washing of remaining solid materials in succession with pure water $(200 \mathrm{~mL})$ and hydrochloric acid $(10 \%, 200 \mathrm{~mL})$, centrifugation (6000 rpm for $4 \mathrm{~h})$ of the filtrate by a centrifuge (TG-16-WS XiangYi centrifuge Instruments Co.) and decantation of the supernatant, were performed. The as-synthesized GO was vacuum-dried overnight at room temperature to yield the desired product.

\section{Preparation of RGO $_{\mathrm{OP}-7 / \mathrm{EGM}}$ sheets}

For the reduction process, dry GO $(500 \mathrm{mg})$ was dispersed in a ratio of $3: 7$ of OP-7/EGM $(60: 140 \mathrm{~mL})$ to obtain a solution with high uniformity and good dispersion. The solution was sonicated in a bath-type sonicator (KQ-50, Kunshan Ultrasonic Instruments Co.) for $3 \mathrm{~h}$ at a power level of $50 \mathrm{~W}$. Hydrazine hydrate $(1 \mathrm{~mL})$ was added, and the mixture was heated at $80{ }^{\circ} \mathrm{C}$ for $3 \mathrm{~h}$ with constant stirring. The finished product was separated by filtration, washed five times with anhydrous ethanol $(400 \mathrm{~mL})$, and vacuum-dried overnight at room temperature to obtain $\mathrm{RGO}_{\mathrm{OP}-7 / \mathrm{EGM}}$ powders. Then, $30 \mathrm{mg}$ of the dried $\mathrm{RGO}_{\mathrm{OP}-7 /}$ EGM powder, prepared according to the previous process, was transferred into a tablet mold with an inner diameter of $10 \mathrm{~mm}$ and then pressurized (15 MPa) by a hydraulic machine (MLN, QJD2518003). RGO $_{\text {OP-7/EGM }}$ sheets can be obtained after holding the pressure for $10 \mathrm{~min}$, followed by demolding.

\section{Preparation of RGO $_{\mathrm{H} 2 \mathrm{O}}$ sheets}

For the reduction process, dry GO $(500 \mathrm{mg})$ was dispersed in pure water and sonicated for $3 \mathrm{~h}$ at a power level of $50 \mathrm{~W}$. Then, $\mathrm{N}_{2} \mathrm{H}_{4} \cdot \mathrm{H}_{2} \mathrm{O}(1 \mathrm{~mL})$ was added and the mixture was heated at $80{ }^{\circ} \mathrm{C}$ for $3 \mathrm{~h}$ with constant stirring. The finished product was separated by filtration and vacuum-dried overnight at room temperature to obtain $\mathrm{RGO}_{\mathrm{H} 2 \mathrm{O}}$ powders. $\mathrm{RGO}_{\mathrm{H} 2 \mathrm{O}}$ sheets can be obtained after holding the pressure (15 MPa) for $10 \mathrm{~min}$, followed by demolding.

\section{Characterization of GO, RGO $\mathrm{OP}_{\mathrm{O}-\mathrm{EGM}}$ and $\mathrm{RGO}_{\mathrm{H} 2 \mathrm{O}}$ sheets}

Fourier transform infrared (FTIR) spectra were recorded on an FTIR spectrometer (Thermo Scientific Nicolet 6700, U.S.) to identify the functional groups. Raman spectra were collected via a confocal microscopic Raman spectrometer (Renishaw InVia Raman microscope, Britain) using a $\times 50$ objective lens at room temperature, with a $530 \mathrm{~nm}$ laser beam and 1800 lines per $\mathrm{mm}$ grating. The UV-vis absorption spectra were recorded by a UVvis spectrometer (Lambda 750 S, U.S.). Measurement of the interlayer distance of the GOs and RGOs was conducted on XRD (D8 Focus $3 \mathrm{KW}$, Bruker AXS, Germany) with $\mathrm{Cu}-\mathrm{K} \alpha$ radiation ( $\lambda$ $=1.5406 \AA$ A). Elemental composition analyses were performed via X-ray photoelectron spectroscopy (XPS, ESCALAB 250Xi) with a monochromatic Al-K $\alpha$ X-ray source at $100 \mathrm{~W}$. The scanned energy has pass energies of $140.00 \mathrm{eV}$, and the highresolution scans have a flux of $26.00 \mathrm{eV}$. The microstructure and crystal structure were observed by field emission transmission electron microscopy (FETEM, JEM-2100F, Japan) and field emission scanning electron microscopy (FESEM, Zeiss Ultra Plus, Germany). Furthermore, selected area electron diffraction (SAED) was performed using FETEM. Sheet resistance $\left(R_{\mathrm{S}}, \Omega \mathrm{sq}^{-1}\right)$ of the RGO sheets was measured by a fourpoint probe method (RTS-8, China), and the corresponding volume conductivity $\left(\sigma, \mathrm{S} \mathrm{m} \mathrm{m}^{-1}\right)$ can be converted using the formula: $\sigma=1 /\left(R_{\mathrm{S}} \times t\right)$, where $t$ indicates the thickness of the RGO sheet. 
(a)

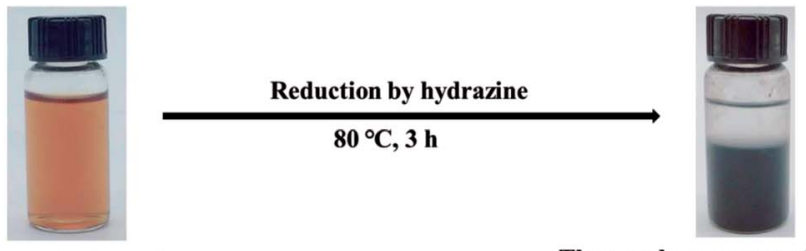

Ultrasonic dispersion

The graphene aggregated together of GO in pure water and had obvious stratification

(b)

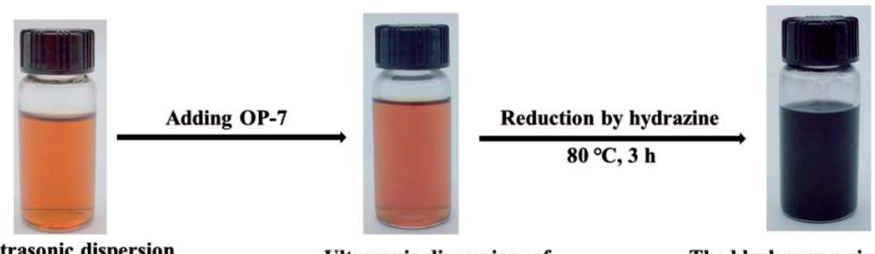

Ultrasonic dispersion

Ultrasonic dispersion of GO in OP-7/EGM (3:7)

The black suspension of graphene was quite stable

(c)
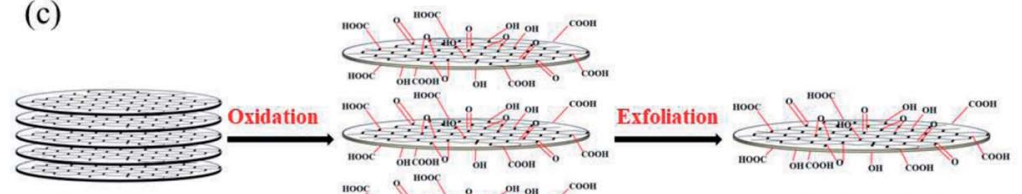

Graphite

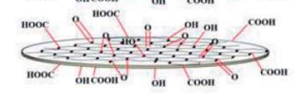

Graphene Oxide

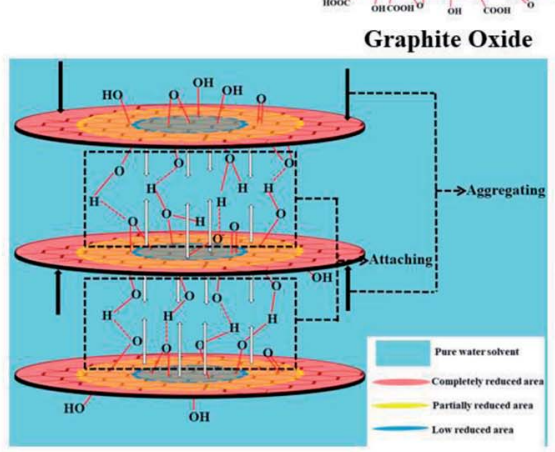

(GO)

Reduced Graphene Oxide (RGO)

(d)

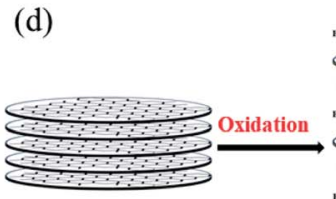

Graphite
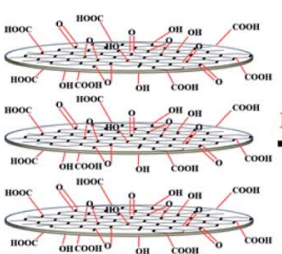

Exfoliation

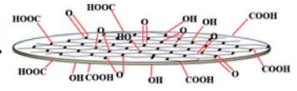

Graphene Oxide

(GO)

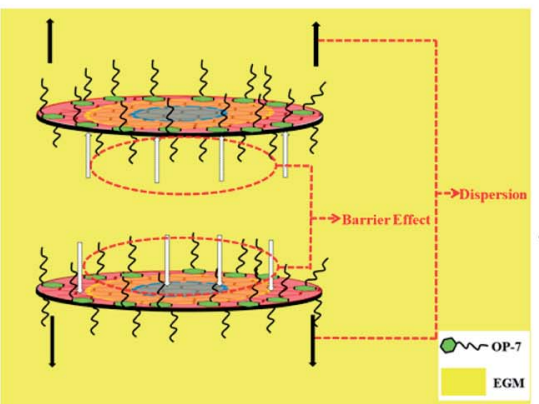

Ultrasonic dispersion in mixed medium of OP-7 and EGM

rasonic dispersion in pure water

Reduction

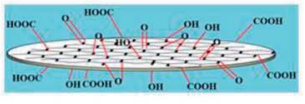

GO dispersion

Reduced Graphene Oxide (RGO)

Fig. 1 Reduction routes of GO in pure water (a) and in the mixed reaction medium (OP-7 and EGM) (b); the cause of aggregation in pure water (c) and the aggregation prevention mechanism in the mixed reaction medium (OP-7 and EGM) (d). 

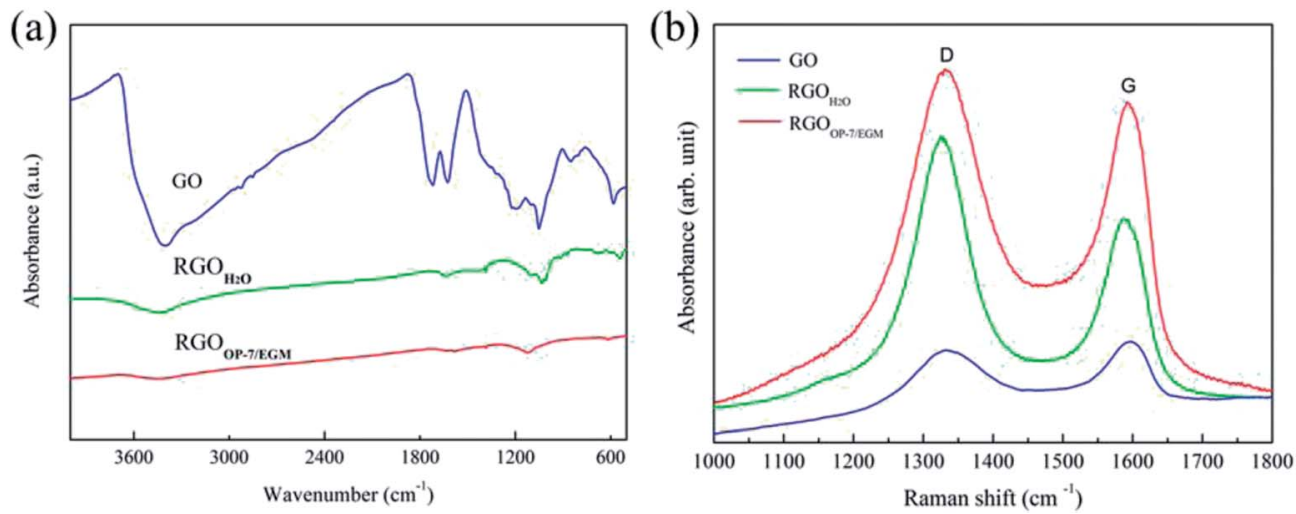

Fig. 2 Fourier transform infrared spectra of $\mathrm{GO}, \mathrm{RGO}_{\mathrm{H} 2 \mathrm{O}}$ and $\mathrm{RGO} \mathrm{OP}-7 / \mathrm{EGM}$ (a) and Raman spectra of GO, $\mathrm{RGO}_{\mathrm{H} 2 \mathrm{O}}$ and $\mathrm{RGO} \mathrm{OP}-7 / \mathrm{EGM}$ (b).

\section{Results and discussion}

Pure water has been used by many groups as a reaction medium to reduce the GO. However, several chemical reduction reactions in pure water cannot bring about effective excellent performance of the resultant GO. The underlying correlation with reaction medium has not been clearly observed. For this purpose, we compared graphene obtained by reduction in pure water and that in OP-7/EGM mixed medium. Fig. 2a shows the Fourier transform infrared spectra, confirming the different functional groups between $\mathrm{GO}, \mathrm{RGO}_{\mathrm{H} 2 \mathrm{O}}$ and $\mathrm{RGO}_{\mathrm{OP}-7 / \mathrm{EGM}}$. The spectrum of GO shows too many peaks: wide and strong $\mathrm{O}-\mathrm{H}$ stretching vibrations $\left(3410 \mathrm{~cm}^{-1}\right), \mathrm{C}=\mathrm{O}$ stretching vibrations (1724 $\left.\mathrm{cm}^{-1}\right), \mathrm{C}=\mathrm{C}$ from $\mathrm{sp}^{2}$ bonds $\left(1628 \mathrm{~cm}^{-1}\right), \mathrm{C}-\mathrm{OH}$ stretching vibrations $\left(1220 \mathrm{~cm}^{-1}\right), \mathrm{C}-\mathrm{O}-\mathrm{C}$ stretching vibrations $\left(1050 \mathrm{~cm}^{-1}\right)$ in epoxy, and epoxy stretching vibrations (853 $\mathrm{cm}^{-1}$ ). The $\mathrm{C}=\mathrm{O}, \mathrm{C}-\mathrm{OH}$ and epoxy stretching vibrations evidently disappeared, indicating that the GO has been reduced. On comparing the spectrum of $\mathrm{RGO}_{\mathrm{OP}-7 / \mathrm{EGM}}$ with that of $\mathrm{RGO}_{\mathrm{H} 2 \mathrm{O}}$, we see that $\mathrm{O}-\mathrm{H}$ and $\mathrm{C}-\mathrm{O}-\mathrm{C}$ stretching vibrations were hardly visible. This indicated that most of the oxygen groups on GO have been removed. This result shows that the edge and center of GO reduced completely under OP-7/EGM mixed reaction medium.

The information of the defects was reflected in the ratio of the intensities of $D$ and $G$ bands $(D: G)$ in the micro-Raman spectra, as shown in Fig. 2b. The $G$ band reflects the symmetry and crystallinity of the material, while the $\mathrm{D}$ band is often called the defect band. It can be seen that the intensity ratio $\left(I_{\mathrm{D}} / I_{\mathrm{G}}\right)$ of $\mathrm{D}$ band and $\mathrm{G}$ band of $\mathrm{GO}$ is lower than the $I_{\mathrm{D}} / I_{\mathrm{G}}$ of $\mathrm{RGO}_{\mathrm{H} 2 \mathrm{O}}$ and $\mathrm{RGO}_{\mathrm{OP}-7 / \mathrm{EGM}}$. This is due to the presence of

Table 1 Raman spectroscopy of G, GO, RGOH2O and RGO OP-7/EGM

\begin{tabular}{llll}
\hline & Raman & & \\
\cline { 2 - 4 } & D band $\left(\mathrm{cm}^{-1}\right)$ & G band $\left(\mathrm{cm}^{-1}\right)$ & $I_{\mathrm{D}} / I_{\mathrm{G}}(\%)$ \\
\hline Graphite & - & - & - \\
GO & 1357 & 1597 & 0.97 \\
RGO $_{\text {H2O }}$ & 1332 & 1587 & 1.37 \\
RGO $_{\text {OP-7/EGM }}$ & 1354 & 1591 & 1.01
\end{tabular}

unpaired defects that remained after the removal of a large number of oxygen-containing functional groups. ${ }^{39}$ Moreover, the $I_{\mathrm{D}} / I_{\mathrm{G}}$ of $\mathrm{RGO}_{\mathrm{H} 2 \mathrm{O}}$ increased more significantly than $\mathrm{RGO}_{\mathrm{OP}-7 /}$ EGM, indicating that $\mathrm{RGO}_{\mathrm{OP}-7 / \mathrm{EGM}}$ has fewer defects after reduction in the mixed reaction medium. This finding shows that OP-7 plays a crucial barrier role in preventing aggregation, which is consistent with previous infrared spectra results. Table 1 lists the physical values of the Raman spectra.

The restoration of $\mathrm{C}=\mathrm{C}$ bonds during reduction was characterized by UV-vis spectrometry. As shown in Fig. 3, GO has a strong absorption peak at $235 \mathrm{~nm}$ and a distinct shoulder at $300 \mathrm{~nm}$. The absorption peak of GO at around $235 \mathrm{~nm}$ gradually red-shifted towards $268 \mathrm{~nm}$ after reduction of GO. Furthermore, the absorbance in the whole spectral region increased, indicating that the $\mathrm{C}=\mathrm{C}$ bonds have been restored. The absorption peak shifted to $275 \mathrm{~nm}$, and the absorption was saturated after reducing in mixed medium, indicating that the reduction had been completed.

The powder XRD patterns of graphite (G) and GO were compared with those of the as-prepared RGOs, as shown in Fig. 4a. $\mathrm{RGO}_{\mathrm{OP}-7}$ and $\mathrm{RGO}_{\mathrm{EGM}}$ were prepared by reducing $\mathrm{GO}$ in pure OP-7 and the pure solution of EGM, respectively; the

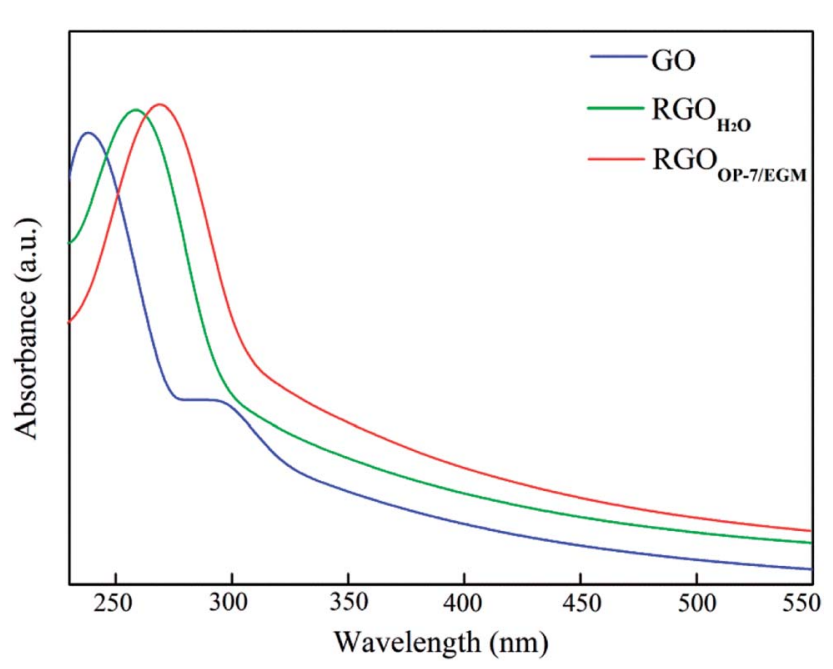

Fig. 3 UV-vis absorption spectra of $\mathrm{GO}, \mathrm{RGO}_{\mathrm{H} 2 \mathrm{O}}$ and $\mathrm{RGO}$ OP-7/EGM. 
(a)

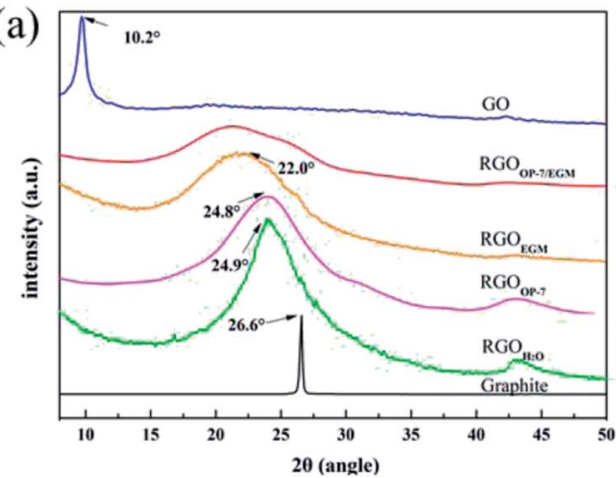

(b)

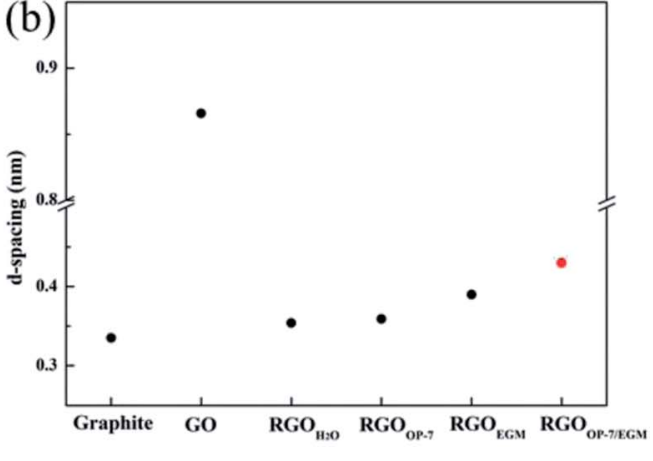

Fig. 4 XRD patterns of GO, Graphite (G) and RGOs (a) and $d$-spacing for the indicated sample types (b).

preparation routes of $\mathrm{RGO}_{\mathrm{OP}-7}$ and $\mathrm{RGO}_{\mathrm{EGM}}$ are shown in Fig. S1. $\dagger$ The peak position for $\mathrm{G}$ was $2 \theta=26.60^{\circ}(d$-spacing $\sim$ $3.35 \AA)$. After the oxidation reaction, GO exhibited a large interlayer distance $\left(d\right.$-spacing $\left.=\sim 8.66 \AA, 2 \theta=10.20^{\circ}\right)$ because of the information of hydroxyl, carboxyl and epoxy groups. There was a significant decrease in the average interlayer distance of RGOs after reduction reaction, as described in Fig. 4 b. Furthermore, Fig. 4 a shows that $\mathrm{RGO}_{\mathrm{H} 2 \mathrm{O}}$ has a distinct sharp peak, and its interlayer distance decreases to $3.54 \AA(2 \theta=$ $24.92^{\circ}$ ), indicating that the $\mathrm{RGO}_{\mathrm{H} 2 \mathrm{O}}$ has an ordered layer structure because of aggregation during the reduction phase. Although OP-7 can effectively prevent the aggregation of graphene, GO tends to agglomerate in a high concentration of OP7 , resulting in a low reduction degree of GO. The XRD spectrum of $\mathrm{RGO}_{\mathrm{OP}-7}$ also displays an evident peak at $2 \theta=24.80^{\circ}(d-$ spacing $=\sim 3.59 \AA)$, which is similar to the peak position of $\mathrm{RGO}_{\mathrm{H} 2 \mathrm{O}}$, indicating that $\mathrm{RGO}_{\mathrm{OP}-7}$ still has a certain layer structure. In addition, the XRD spectrum of $\mathrm{RGO}_{\mathrm{EGM}}$ has no visible sharp peak, but an inconspicuous broad peak. The interlayer distance of $\mathrm{RGO}_{\mathrm{EGM}}$ was $3.94 \AA\left(2 \theta=22.55^{\circ}\right)$, which was higher than that of $\mathrm{RGO}_{\mathrm{OP}-7}$ because the solution of EGM can effectively disperse GO. However, the layered structure still exists in $\mathrm{RGO}_{\mathrm{EGM}}$ because the dispersion of graphene in EGM was not so ideal. If we only simply satisfy the good dispersion of GO or prevent graphene aggregation, it will be difficult to prepare graphene with good properties. Based on a comparison with interlayer spacing of graphene previously prepared by chemical reduction methods, we found that the spacing of the graphene layers was between $3.57 \AA$ and $3.90 \AA$, while they all had a distinct sharp diffraction peak..$^{27-30,36}$ On the contrary, a dispersing and broad diffraction peak between $22.0^{\circ}$ and $26.9^{\circ}$ can be observed in the XRD pattern of $\mathrm{RGO}_{\mathrm{OP}-7 / \mathrm{EGM}}$. This shows that $\mathrm{RGO}_{\mathrm{OP}-7 / \mathrm{EGM}}$ has no typical layered structure because of the barrier effect of OP-7 and the good dispersion action of EGM. As shown in Fig. S2, $\dagger$ we calculated that the distance between the donor hydrogen and the acceptor oxygen atoms bonded to different functional groups of two graphene sheets was between $3.63 \AA$ and $4.05 \AA$ A. This calculated result was consistent with the layer spacing of graphene prepared by the previous chemical methods and indicated that the individual graphene layers fit with each other via hydrogen bonds mediated by oxygencontaining functional groups. The average interlayer distance of $\mathrm{RGO}_{\mathrm{OP}-7 / \mathrm{EGM}}$ was $4.21 \AA$, corresponding to the red dot in Fig. $4 \mathrm{~b}$, which was higher than $4.05 \AA$ owing to the prevention of the formation of hydrogen bonds by OP-7. In general, the barrier effect of OP-7 and the dispersion effect of EGM are indispensable in the preparation of graphene.

The $\mathrm{C} / \mathrm{O}$ ratio and information about various functional groups of $\mathrm{GO}, \mathrm{RGO}_{\mathrm{H} 2 \mathrm{O}}$ and $\mathrm{RGO}_{\mathrm{OP}-7 / \mathrm{EGM}}$ were investigated by $\mathrm{X}$ ray photoemission spectroscopy (XPS). In Fig. 5a, the O 1 s peak and $\mathrm{C} 1 \mathrm{~s}$ peak positions are observed at $284.8 \mathrm{eV}$ and $533.0 \mathrm{eV}$, respectively. Through the comparison of $\mathrm{GO}$ and $\mathrm{RGO}_{\mathrm{H} 2 \mathrm{O}}$, we found that the intensity of the $\mathrm{O} 1 \mathrm{~s}$ peak of $\mathrm{RGO}_{\mathrm{H} 2 \mathrm{O}}$ visibly decreased in the broad region. This implied that the $\mathrm{C} / \mathrm{O}$ ratio of RGO increased significantly after reduction due to the removal of oxygen-containing groups. In addition, the intensity of the $\mathrm{O}$

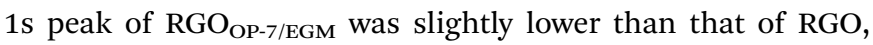
suggesting that $\mathrm{RGO}_{\mathrm{OP}-7 / \mathrm{EGM}}$ was reduced more completely. Fig. $5 \mathrm{~b}$ shows the $\mathrm{C} 1 \mathrm{~s}$ spectrum of $\mathrm{GO}$, which reveals that it consists of two main components arising from the $\mathrm{C}=\mathrm{C} / \mathrm{C}-\mathrm{C}$ $(284.6 \mathrm{eV})$ and $\mathrm{C}=\mathrm{O}$ (carbonyl, $\sim 288.3 \mathrm{eV})$ groups and two minor components from the $\mathrm{C}-\mathrm{O}$ (hydroxyl and epoxy, 286.5 $\mathrm{eV}$ ) and $\mathrm{O}-\mathrm{C}=\mathrm{O}$ (carboxyl, $\sim 290.3 \mathrm{eV}$ ) groups..$^{40}$ After reduction by the traditional chemical method, the C 1s XPS spectrum of $\mathrm{RGO}_{\mathrm{H} 2 \mathrm{O}}$ also displayed these peaks, but their intensities were much lower than those of GO (Fig. 5c), indicating that most of the oxygen functional groups were removed. Most of the $\mathrm{C}=\mathrm{O}$ bonds (carbonyl groups, $\sim 286.9 \mathrm{eV}$ ) were converted into $\mathrm{C}-\mathrm{O}$ bonds (hydroxyl groups, $\sim 286.1 \mathrm{eV}$ ), and a number of carboxyl groups were removed. By using mixed reaction medium of OP-7 and EGM, all of the carbonyl groups of $\mathrm{RGO}_{\mathrm{OP}-7 / \mathrm{EGM}}$ were almost completely removed, and the $\mathrm{C}-\mathrm{O}$ bonds were reduced, as shown in Fig. 5d. Compared with $\mathrm{RGO}_{\mathrm{H} 2 \mathrm{O}}$, the reduction degree of $\mathrm{RGO}_{\mathrm{OP}-\mathrm{T} / \mathrm{EGM}}$ is higher. Areas of the contributing peaks are listed in Table 2. The atomic ratio of $\mathrm{C} / \mathrm{O}$ increased from 1.70 for GO to 9.04 for $\mathrm{RGO}_{\mathrm{OP}-7 / \mathrm{EGM}}$, which was higher than the value for the $\mathrm{RGO}_{\mathrm{H} 2 \mathrm{O}}$ obtained by reduction in pure water. The $\mathrm{C}-\mathrm{C}$ groups of $\mathrm{RGO}_{\mathrm{OP}-7 / \mathrm{EGM}}$ compared with $\mathrm{RGO}_{\mathrm{H} 2 \mathrm{O}}$ increased substantially, while the $\mathrm{C}-\mathrm{O}$ and $\mathrm{C}=\mathrm{O}$ groups decreased significantly and the $\mathrm{O}-\mathrm{C}=\mathrm{O}$ groups disappeared completely. These results show that $\mathrm{RGO}_{\mathrm{OP}-7 / \mathrm{EGM}}$ was reduced much better than $\mathrm{RGO}_{\mathrm{H} 2 \mathrm{O}}$, which is consistent with the XRD spectra due to the barrier effect of surfactant OP-7 and the great dispersion action of EGM. 
(a)

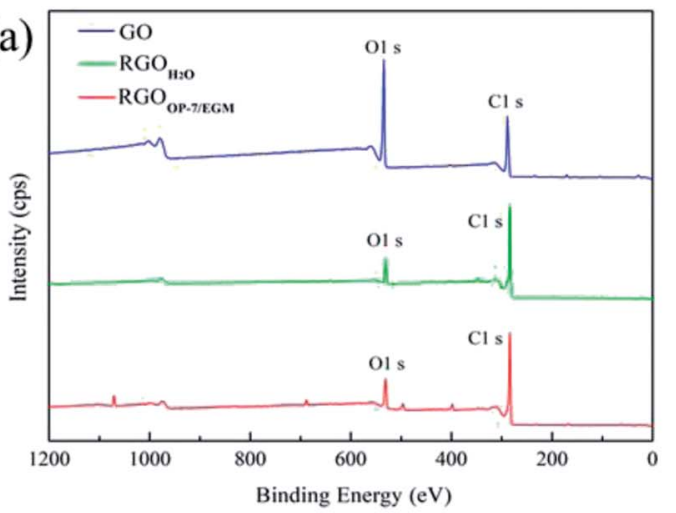

(c)

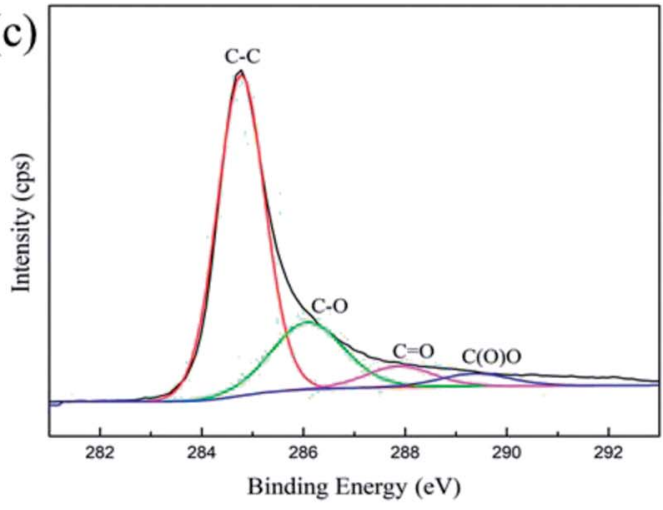

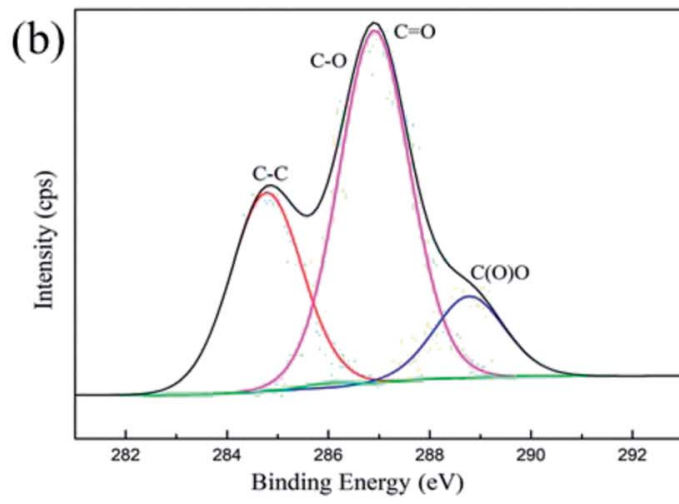

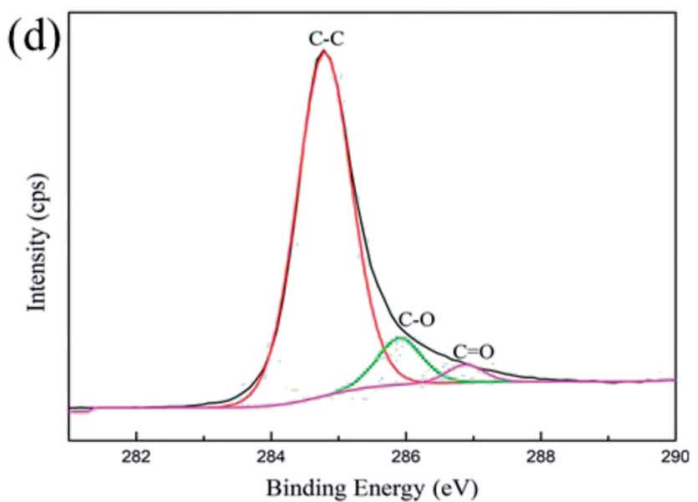

Fig. 5 XPS spectra of $\mathrm{GO}, \mathrm{RGO}_{\mathrm{H} 2 \mathrm{O}}$ and $\mathrm{RGO} \mathrm{OP-7/EGM}$ : wide region (a) and $\mathrm{C}$ 1s region of $\mathrm{GO}$ (b), $\mathrm{RGO}_{\mathrm{H} 2 \mathrm{O}}$ (c) and $\mathrm{RGO}$ OP-7/EGM (d).

As shown in Fig. 6a, a field emission scanning electron microscopy (FESEM) image of the surface of the $\mathrm{RGO}_{\mathrm{H} 2 \mathrm{O}}$ power sample exhibited many stacks due to aggregation. On the contrary, a clearly single-layer structure of the RGO sheet is observed in Fig. 6b. Fig. 6c shows the field emission transmission electron microscopy (FETEM) image of the $\mathrm{RGO}_{\mathrm{H} 2 \mathrm{O}}$ sheets; we can find that the $\mathrm{RGO}_{\mathrm{H} 2 \mathrm{O}}$ sheets overlapped and aggregated into a multilayer structure. Fig. 6d and e show the TEM images of the $\mathrm{RGO}_{\text {OP-7/EGM }}$ platelets at different magnifications, respectively. Although a few folds appear on the $\mathrm{RGO}_{\text {OP-7/EGM }}$ sheets, most of the graphene sheets were single-layer or few-layer owing to the complementary role of OP-7 and EGM. As can be seen in Fig. 6f, the selected area electron diffraction (SAED) pattern distinctly indicates the graphitic crystalline structure. The first ring came from the (1100) plane, and the bright spots consistent with the (1100) reflections retained the hexagonal symmetry of the [0001] diffraction pattern. Furthermore, we found that the relative strength of the inner and outer spot rings was close, corresponding to the structure of single-layer graphene or few layer graphene.

Table 3 summarizes the electrical conductivity of $\mathrm{RGO}_{\mathrm{H} 2 \mathrm{O}}$, $\mathrm{RGO}_{\mathrm{OP}-7}, \mathrm{RGO}_{\mathrm{EGM}}$ and $\mathrm{RGO}_{\mathrm{OP}-7 / \mathrm{EGM}}$ sheets dried at room temperature. The conductivity of $\mathrm{RGO}_{\mathrm{H} 2 \mathrm{O}}$ was only $1050 \mathrm{~S} \mathrm{~m}^{-1}$ because hydrophobic graphene sheets were easily aggregating in an aqueous environment. The conductivity of $\mathrm{RGO}_{\mathrm{OP}-7}$ was $1400 \mathrm{~S} \mathrm{~m}^{-1}$, which was similar to that of $\mathrm{RGO}_{\mathrm{H} 2 \mathrm{O}}$, because GO tended to aggregate in a high concentration of OP-7, resulting in a low reduction degree of GO. Although the conductivity of $\mathrm{RGO}_{\mathrm{EGM}}$ increased to $3770 \mathrm{~S} \mathrm{~m}^{-1}$, the poor dispersion of graphene in EGM led to non-ideal conductivity. With the use of the mixed reaction medium of OP-7 and EGM, the conductivity of $\mathrm{RGO}_{\mathrm{OP}-7 / \mathrm{EGM}}$ was $14000 \mathrm{~S} \mathrm{~m}^{-1}$, showing an over tenfold increase with respect to the $\mathrm{RGO}_{\mathrm{H} 2 \mathrm{O}}$ value due to the interactions between the barrier effect of OP-7 and the good dispersion action of EGM. This result is consistent with the previous test results.

Table 2 The $\mathrm{C}$ 1s peak position and the relative atomic percentage of various functional groups in $\mathrm{GO}, \mathrm{RGO}_{\mathrm{H} 2 \mathrm{O}}$ and $\mathrm{RGO} \mathrm{OP}_{-7 / \mathrm{EGM}}$

\begin{tabular}{lllll}
\hline & \multicolumn{2}{l}{ Fitting of the C 1s peak binding energy [eV] (relative atomic percentage [\%]) } & \multicolumn{2}{c}{ XPS } \\
\cline { 2 - 4 } & $\mathrm{C}-\mathrm{C}$ & $\mathrm{C}-\mathrm{O} / \mathrm{C}-\mathrm{O}-\mathrm{C}$ & $\mathrm{C}=\mathrm{O}$ & $\mathrm{O}-\mathrm{C}=\mathrm{O}$ \\
\hline $\mathrm{GO}$ & $284.78(31.55)$ & $286.01(1.48)$ & $286.91(55.33)$ & $288.78(11.64)$ \\
$\mathrm{RGO}_{\mathrm{H} 2 \mathrm{O}}$ & $284.77(67.98)$ & $286.08(21.74)$ & $287.88(6.30)$ & $289.38(3.98)$ \\
$\mathrm{RGO}_{\mathrm{OP}-7 / \mathrm{EGM}}$ & $284.79(89.33)$ & $285.90(8.62)$ & $286.88(2.05)$ & -
\end{tabular}


(a)

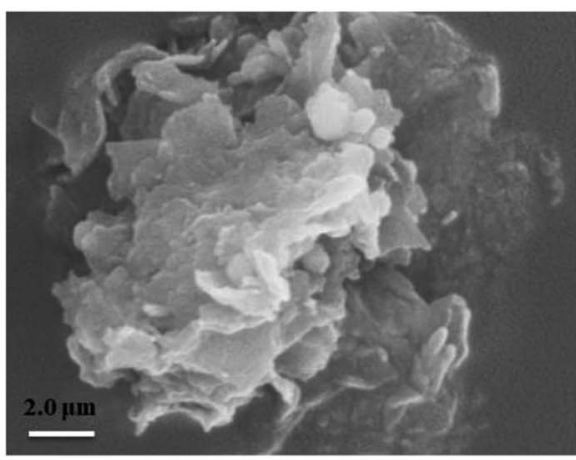

(c)

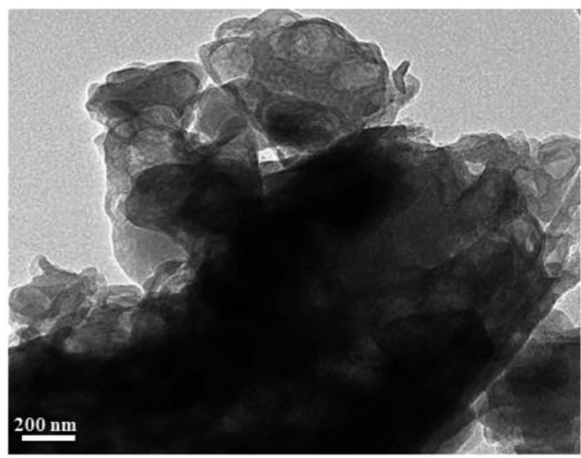

(e)

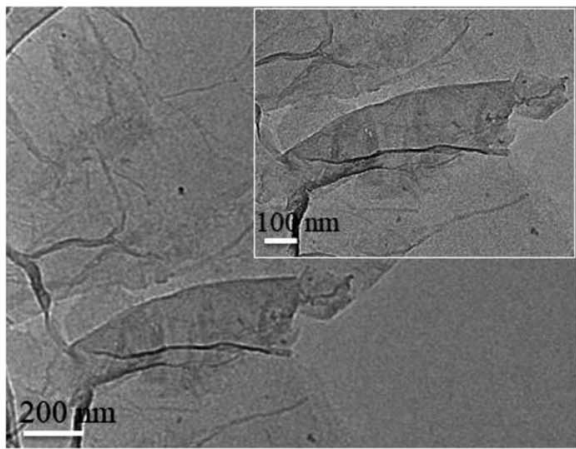

(b)

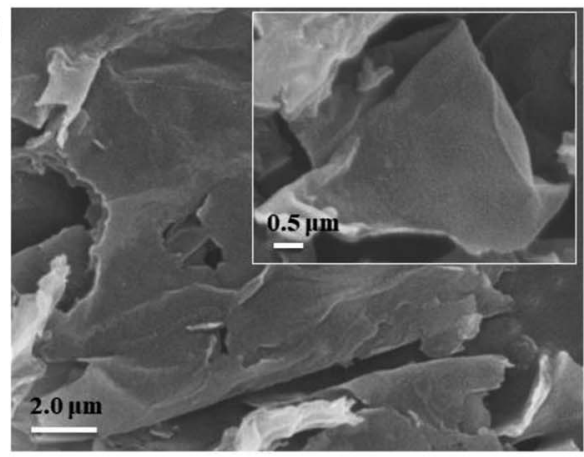

(d)

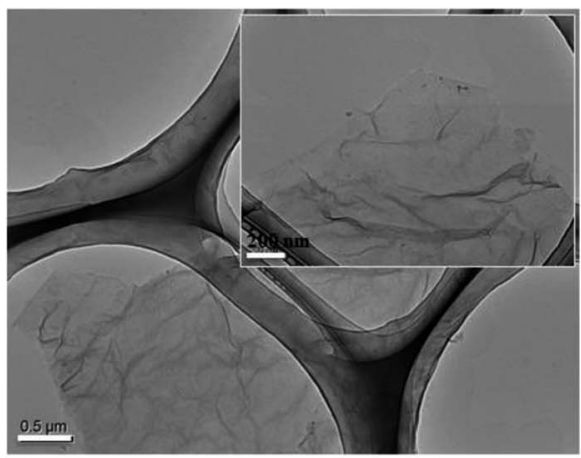

(f)

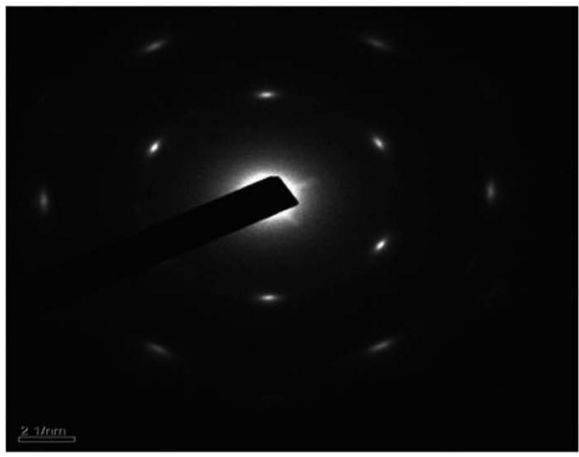

Fig. 6 SEM images of $\mathrm{RGO}_{\mathrm{H} 2 \mathrm{O}}$ (a) and $\mathrm{RGO}$ OP-7/EGM (b), TEM image of $\mathrm{RGO}_{\mathrm{H} 2 \mathrm{O}}$ (c), TEM images of $\mathrm{RGO}_{\mathrm{OP}-7 / E G M}$ (d) and (e) at different magnifications, SAED pattern of RGOOP-7/EGM platelet (f).

Table 3 Electrical conductivities of $\mathrm{RGO}_{\mathrm{H} 2 \mathrm{O}}, \mathrm{RGO}_{\mathrm{OP}-7}, \mathrm{RGO}_{\mathrm{EGM}}$ and RGOOP-7/EGM sheets

\begin{tabular}{lll}
\hline $\begin{array}{l}\text { Reduced graphene } \\
\text { oxide }\end{array}$ & Drying temperature & $\begin{array}{l}\text { Conductivity } \\
\left(\mathrm{S} \mathrm{m}^{-1}\right)\end{array}$ \\
\hline $\mathrm{RGO}_{\mathrm{H} 2 \mathrm{O}}$ & Room temperature & 1050 \\
$\mathrm{RGO}_{\mathrm{OP}-7}$ & Room temperature & 1400 \\
$\mathrm{RGO}_{\mathrm{EGM}}$ & Room temperature & 3770 \\
$\mathrm{RGO}_{\mathrm{OP}-7 / \mathrm{EGM}}$ & Room temperature & 14000 \\
\end{tabular}

Table 4 summarizes the electrical conductivity of the $\mathrm{RGO}_{\mathrm{OP}-7 / \mathrm{EGM}}$ power pellets and graphene power pellets or freestanding paper samples under different reduction conditions. In contrast to the electrical conductivity reported previously for modified graphene reduced by different chemical methods, our $\mathrm{RGO}_{\mathrm{OP}-7 / \mathrm{EGM}}$ power pellet had a high electrical conductivity $\left(14000 \mathrm{~S} \mathrm{~m}^{-1}\right)$, which was almost 70 times that of graphene reduced by hydrazine $\left(200 \mathrm{~S} \mathrm{~m}^{-1}\right)$, and achieved a higher value without treatment at high-temperatures. The conductivity of $\mathrm{RGO}_{\mathrm{HI}-\mathrm{AcOH}}$ reduced by hydroiodic acid (HI) in

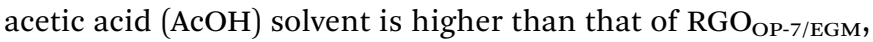
the final conductivity of graphene may be different due to the differences in the reduction system. Our method of reduction in the mixed medium of OP-7 and EGM is a simple separation process, involves mild reaction conditions and short reduction time, and exhibits great reproducibility. The high electrical conductivity of $\mathrm{RGO}_{\mathrm{OP}-7 / \mathrm{EGM}}$ was attributed to the avoidance of aggregation because of the barrier effect of surfactant OP-7 and the good dispersion action of the organic solvent EGM. The electrical conductivity of $\mathrm{RGO}_{\mathrm{OP}-7 / \mathrm{EGM}}$ with $220{ }^{\circ} \mathrm{C}$ treatment reached $15800 \mathrm{~S} \mathrm{~m}^{-1}$, which was higher than that of the $\mathrm{RGO}_{\mathrm{OP}-7 / \mathrm{EGM}}$ sheet $\left(14000 \mathrm{~S} \mathrm{~m}^{-1}\right)$ obtained via room temperature treatment. We consider that the increase in electrical conductivity could be attributed to the escape and volatilization of some organic matter or adsorbate on the surface of $\mathrm{RGO}_{\mathrm{OP}-7 / \mathrm{EGM}}$. 
Table 4 Electrical conductivities of the RGO power pellet and free-standing paper samples of modified graphene

\begin{tabular}{|c|c|c|c|c|}
\hline Reduced graphene oxide & $\begin{array}{l}\text { Reduction } \\
\text { temperature }\left({ }^{\circ} \mathrm{C}\right)\end{array}$ & $\begin{array}{l}\text { Reduction } \\
\text { time (h) }\end{array}$ & Drying temperature $\left({ }^{\circ} \mathrm{C}\right)$ & $\begin{array}{l}\text { Conductivity } \\
\left(\mathrm{S} \mathrm{m}^{-1}\right)\end{array}$ \\
\hline $\mathrm{RGO}_{\mathrm{OP}-7 / \mathrm{EGM}}$ & 80 & 3 & $\begin{array}{l}\text { Room temperature } \\
220\end{array}$ & $\begin{array}{l}14000 \\
15800\end{array}$ \\
\hline $\begin{array}{l}\text { Reduced graphene oxide by } \\
\text { hydrazine }\end{array}$ & 80 & 24 & 60 & 200 \\
\hline $\mathrm{RGO}_{\mathrm{HI}-\mathrm{AcOH}}{ }^{28}$ & 40 & 40 & Room temperature & 30400 \\
\hline $\mathrm{HRG}^{36}$ & 80 & 12 & $\begin{array}{l}\text { Room temperature } \\
150\end{array}$ & $\begin{array}{l}1700 \\
16000\end{array}$ \\
\hline $\mathrm{CCG}^{31,32}$ & 95 & 1 & $\begin{array}{l}\text { Room temperature } \\
220\end{array}$ & $\begin{array}{l}7200 \\
11800\end{array}$ \\
\hline CCG2 (ref. 25) & 120 & 12 & Room temperature & 1600 \\
\hline
\end{tabular}

\section{Conclusions}

In summary, we have analyzed the aggregation of graphene during the chemical reduction method and reported the method to prevent the aggregation of graphene. In addition, the potential reduction mechanism and the root cause for the aggregation of graphene have been addressed. RGO $_{\text {OP-7/EGM }}$ was reduced from GO with hydrazine hydrate in a mixed medium of OP-7 and EGM. EGM provided a good dispersion environment for GO, and OP-7 could effectively prevent superimposed aggregation. Furthermore, the XRD spectrum of $\mathrm{RGO}_{\mathrm{OP}-7 / \mathrm{EGM}}$ shows a dispersing diffraction peak, indicating that there was no typical layer structure. The $\mathrm{RGO}_{\mathrm{OP}-7 / \mathrm{EGM}}$ sheet obtained via room temperature treatment had an electrical conductivity value as high as $14000 \mathrm{~S} \mathrm{~m}^{-1}$.

\section{Conflicts of interest}

We declare that we have no financial and personal relationships with other people or organizations that can inappropriately influence our work. There is no professional or other personal interest of any nature or kind in any product, service and/or company that could be construed as influencing the position presented in, or the review of, the manuscript entitled, "Aggregation Prevention: Reduction of Graphene Oxide in Mixed Medium of Alkylphenol Polyoxyethylene (7) Ether and 2Methoxyethanol".

\section{Acknowledgements}

This study was financially supported by the National Natural Science Foundation of China (51273155).

\section{References}

1 A. K. Geim, Science, 2009, 324, 1530-1534.

2 A. K. Geim and K. S. Novoselov, Nat. Mater., 2007, 6, 183-191. 3 S. Ramirez, K. Chan, R. Hernandez, E. Recinos, E. Hernandez, R. Salgado, A. G. Khitun, J. E. Garay and A. A. Balandin, Mater. Des., 2017, 118, 75-80.
4 X. Wang, L. Zhi and K. Müllen, Nano Lett., 2008, 8, 323-327. 5 R. Verma, S. Bhattacharya and S. Mahapatra, IEEE Trans. Electron Devices, 2013, 60, 2695-2698.

6 C. N. R. Rao, A. K. Sood, K. S. Subrahmanyam and A. Govindaraj, Angew. Chem., Int. Ed., 2009, 48, 52-77.

7 H. Bai, C. Li and G. Shi, Adv. Mater., 2011, 23, 1089-1115.

8 B. Guo, L. Fang, B. Zhang and J. R. Gong, Insci. J., 2011, 40, 80-89.

9 H. Spanggaard and F. C. Krebs, Sol. Energy Mater. Sol. Cells, 2004, 83, 125-146.

10 G. Wang, X. Shen, J. Yao and J. Park, Carbon, 2009, 47, 20492053.

11 W. Bower, W. Head, G. T. R. Droop, R. Zan, R. A. D. Pattrick, P. Wincott and S. J. Haigh, Mineral. Mag., 2015, 79, 337-344.

12 K. Kim, J. Park, C. Kim, W. Choi, Y. Seo, J. Ahn and I. Park, Micro Nano Lett., 2012, 7, 1133.

13 J. N. Coleman, M. Lotya, A. O'Neill, S. D. Bergin, P. J. King, U. Khan, K. Young, A. Gaucher, S. De, R. J. Smith, I. V. Shvets, S. K. Arora, G. Stanton, H. Y. Kim, K. Lee, G. T. Kim, G. S. Duesberg, T. Hallam, J. J. Boland, J. J. Wang, J. F. Donegan, J. C. Grunlan, G. Moriarty, A. Shmeliov, R. J. Nicholls, J. M. Perkins, E. M. Grieveson, K. Theuwissen, D. W. McComb, P. D. Nellist and V. Nicolosi, Science, 2011, 331, 568-571.

14 D. Long, W. Li, L. Ling, J. Miyawaki, I. Mochida and S. Yoon, Langmuir, 2010, 26, 16096-16102.

15 S. Pei and H. Cheng, Carbon, 2012, 50, 3210-3228.

16 D. Chen, H. Feng and J. Li, Chem. Rev., 2012, 112, 6027-6053. 17 S. Pei, J. Zhao, J. Du, W. Ren and H. Cheng, Carbon, 2010, 48, 4466-4474.

18 R. Iguchi, T. Kawamura, Y. Suzuki, M. Inoue, Y. Kangawa and K. Kakimoto, Jpn. J. Appl. Phys., 2014, 53, 65601.

19 Z. Juang, C. Wu, C. Lo, W. Chen, C. Huang, J. Hwang, F. Chen, K. Leou and C. Tsai, Carbon, 2009, 47, 2026-2031.

20 B. Hu, H. Ago, Y. Ito, K. Kawahara, M. Tsuji, E. Magome, K. Sumitani, N. Mizuta, K. Ikeda and S. Mizuno, Carbon, 2012, 50, 57-65.

21 M. Batzill, Surf. Sci. Rep., 2012, 67, 83-115.

22 W. S. Hummers Jr and R. E. Offeman, J. Am. Chem. Soc., 1958, 80, 1339. 
23 L. Tang, Y. Wang, Y. Li, H. Feng, J. Lu and J. Li, Adv. Funct. Mater., 2009, 19, 2782-2789.

24 A. F. Morpurgo, H. B. Heersche, L. M. K. Vandersypen, X. Liu and J. B. Oostinga, Nat. Mater., 2008, 7, 151-157.

25 W. Gao, L. B. Alemany, L. Ci and P. M. Ajayan, Nat. Chem., 2009, 1, 403-408.

26 S. Pei, J. Zhao, J. Du, W. Ren and H. Cheng, Carbon, 2010, 48, 4466-4474.

27 H. Shin, K. K. Kim, A. Benayad, S. Yoon, H. K. Park, I. Jung, M. H. Jin, H. Jeong, J. M. Kim, J. Choi and Y. H. Lee, $A d v$. Funct. Mater., 2009, 19, 1987-1992.

28 I. K. Moon, J. Lee, R. S. Ruoff and H. Lee, Nat. Commun., 2010, 1, 1-6.

29 Z. Fan, K. Wang, T. Wei, J. Yan, L. Song and B. Shao, Carbon, 2010, 48, 1686-1689.

30 V. H. Pham, T. V. Cuong, T. D. Nguyen-Phan, H. D. Pham, E. J. Kim, S. H. Hur, E. W. Shin, S. Kim and J. S. Chung, Chem. Commun., 2010, 46, 4375-4377.

31 D. Li, M. B. Mã Ller, S. Gilje, R. B. Kaner and G. G. Wallace, Nat. Nanotechnol., 2008, 3, 101-105.
32 H. Chen, M. B. Müller, K. J. Gilmore, G. G. Wallace and D. Li, Adv. Mater., 2008, 20, 3557-3561.

33 C. Bao, L. Song, W. Xing, B. Yuan, C. A. Wilkie, J. Huang, Y. Guo and Y. Hu, J. Mater. Chem., 2012, 22, 688-696.

34 S. Park, J. An, R. D. Piner, I. Jung, D. Yang, A. Velamakanni, S. T. Nguyen and R. S. Ruoff, Chem. Mater., 2008, 20, 65926594.

35 V. H. Luan, H. N. Tien, L. T. Hoa, N. T. M. Hien, E. Oh, J. Chung, E. J. Kim, W. M. Choi, B. Kong and S. H. Hur, J. Mater. Chem. A, 2013, 1, 208-211.

36 S. Park, J. An, I. Jung, R. D. Piner, S. J. An, X. Li, A. Velamakanni and R. S. Ruoff, Nano Lett., 2009, 9, 15931597.

37 D. Chen, H. Feng and J. Li, Chem. Rev., 2012, 112, 6027-6053. 38 X. Gao, J. Jang and S. Nagase, J. Phys. Chem. C, 2009, 114, 832-842.

39 Y. Zhou, Q. Bao, L. A. L. Tang, Y. Zhong and K. P. Loh, Chem. Mater., 2009, 21, 2950-2956.

40 S. Stankovich, D. A. Dikin, R. D. Piner, K. A. Kohlhaas, A. Kleinhammes, Y. Jia, Y. Wu, S. T. Nguyen and R. S. Ruoff, Carbon, 2007, 45, 1558-1565. 